\title{
Risk and return spillovers among the G10 currencies
}

\author{
Matthew Greenwood-Nimmo ${ }^{\mathrm{a}}$, Viet Hoang Nguyen ${ }^{\mathrm{b}}$, Barry Rafferty ${ }^{\mathrm{a}, *}$ \\ ${ }^{a}$ Department of Economics, University of Melbourne, 111 Barry Street, Melbourne 3053, Australia. \\ ${ }^{b}$ Melbourne Institute of Applied Economic \& Social Research, 111 Barry Street, Melbourne 3053, Australia.
}

\begin{abstract}
We study spillovers among daily returns and innovations in the option-implied risk-neutral volatility and skewness of the G10 currencies. Using an empirical network model, we uncover substantial time variation in the interaction of returns and risk measures, both within and between currencies. We find that aggregate spillover intensity is countercyclical with respect to the federal funds rate and increases in periods of financial stress. Cross-currency spillovers of volatility and especially of skewness increase in times of stress, reflecting greater systematic risk. Similarly, in such times, returns become more sensitive to risk measures and vice versa.
\end{abstract} Keywords: Foreign exchange markets, risk-neutral volatility, risk-neutral skewness, spillovers, coordinated crash risk.

JEL classifications: C58, F31, G01, G15.

\footnotetext{
*Corresponding author. Tel.: +61 (0)3-8344-7198.

Email addresses: matthew.greenwood@unimelb.edu.au (Matthew Greenwood-Nimmo), vietn@unimelb.edu.au (Viet Hoang Nguyen), barry.rafferty@unimelb.edu.au (Barry Rafferty)
} 


\section{Introduction}

To what extent are currency markets connected to one another? This is a central question facing foreign exchange (FX) investors as they form and manage portfolios conditional on the risk-return profiles of a basket of currencies, typically seeking to manage their exposure to idiosyncratic risk through diversification. Changes in currencies' risk-return profiles will often induce portfolio rebalancing. However, in the act of rebalancing, investors' collective actions are likely to further change the risk-return profiles. This feedback effect will induce a complex array of interactions - or spillovers - among currency returns and a variety of risk measures, both within and between currency markets. Network analysis provides a natural framework to study such complex dynamic phenomena (Diebold and Yilmaz, 2009, 2014; Billio et al., 2012). However, network models remain scarce in the FX literature. We therefore develop an empirical network model to study risk and return spillovers within and between the major global currencies.

Given the importance of portfolio rebalancing in the network dynamics of FX markets, our model has two salient features. First, since FX portfolios are typically composed of several currencies, we work with a comprehensive panel dataset covering the G10 currencies. These currencies are among the world's most actively traded and liquid, collectively accounting for the large majority of turnover in global FX markets. ${ }^{1}$ This extensive cross-sectional coverage of FX markets allows us to capture the large majority of investors' rebalancing activities. Second, to account for the different types of risk that currency investors face, we follow the emphasis in the FX asset pricing literature and include both the volatility and the skewness of changes in the exchange rate within our model. Specifically, since portfolio rebalancing is forward-looking, our analysis is based on forward-looking measures of volatility and skewness extracted from FX options data.

\footnotetext{
${ }^{1}$ This can be clearly seen in the triennial survey of turnover in foreign exchange markets published by the Bank for International Settlements, the most recent of which is available at http://www.bis.org/publ/ $\operatorname{rpfx} 13 f x \cdot p d f$.
} 
Volatility has long been used as a measure of uncertainty and a sophisticated literature has documented the linkage between returns and volatility. For example, Menkhoff et al. (2012) show that differences in exposure to innovations in an aggregate measure of global FX volatility play an important role in explaining the cross-sectional differences in the average excess returns of interest rate sorted currency portfolios and, therefore, in the average excess return to the carry trade strategy. Changes in global FX volatility have also been shown to be predictive of carry trade returns in the time series dimension by Bakshi and Panayotov (2013).

Skewness, meanwhile, measures crash risk, the risk associated with large jumps or crashes in the exchange rate, whether depreciations or appreciations. Crash risk has gained prominence as a factor underlying the high average excess returns to various currency strategies. A negative cross-sectional relation between interest rate differentials and currency skewness has been documented at the individual currency level by Brunnermeier, Nagel, and Pedersen (2009) and Jurek (2014). Furthermore, Rafferty (2012) demonstrates that exposure to a global FX skewness measure explains a large proportion of the high average excess returns not just to the carry trade but also to currency momentum and value strategies. Rafferty's approach captures the risk of a coordinated crash, in which high-yield investment currencies sharply depreciate and low-yield funding currencies simultaneously appreciate. Coordinated crashes were observed during the recent global financial crisis (GFC), as funding liquidity constraints led to the sudden unwinding of carry trades. ${ }^{2}$

Our use of option-implied volatility and skewness accords with recent developments in the literature and confers several significant benefits relative to the use of latent or realized measures of volatility and skewness (Chang, Christoffersen, and Jacobs, 2013; Christoffersen, Jacobs, and Chang, 2013; Conrad, Dittmar, and Ghysels, 2013). Since they are computed

\footnotetext{
${ }^{2}$ In related work, other researchers evaluate the importance of crash risk by comparing the returns to unhedged versus option-hedged carry trades (e.g., Burnside, Eichenbaum, Kleshchelski, and Rebelo, 2011; Jurek, 2014). The results indicate that much of the average excess return to the carry trade may be attributed to crash risk.
} 
every day using one day of options prices, our option-implied series provide truly conditional market-based estimates of the risk-neutral expected volatility and skewness that investors anticipate over the options' maturity. As such, the option-implied measures capture investors' beliefs and risk preferences in a forward-looking manner, thereby providing ex ante measures of expected volatility and skewness.

To recover the moments of the option-implied (risk-neutral) distribution of future exchange rate changes, we use the model-free methodology of Bakshi and Madan (2000), Carr and Madan (2001), and Bakshi, Kapadia, and Madan (2003). ${ }^{3}$ In this way, we construct daily option-implied measures of volatility and skewness for each of the G10 currencies against the U.S. dollar over the period from January 1999 to October 2014 using a rich dataset of FX options prices obtained from J.P. Morgan. To account for the autocorrelation structure of the risk-neutral moments, we follow the precedent established by Menkhoff et al. (2012) in the FX literature, and Chang et al. (2013) in the equity literature, and extract the innovations in the risk-neutral volatility (RNV) and risk-neutral skewness (RNS) of exchange rate changes based on auxiliary first order autoregressions.

Our empirical results are derived from a generalization of the connectedness framework developed by Diebold and Yilmaz $(2009,2014)$, in which one infers the structure of a network based on forecast error variance decomposition of an underlying vector autoregression. The generalization that we employ is due to Greenwood-Nimmo, Nguyen, and Shin (2015a), whose method accommodates arbitrary aggregations of the connectedness matrix. The benefit of this approach is that it provides a means to transform the connectedness matrix to directly capture connectedness among groups of variables, as opposed to connectedness among individual variables. In this way, we are free to focus the analysis at any desired level of aggregation. For example, we may evaluate connectedness among currency markets,

\footnotetext{
${ }^{3}$ There is now a sizeable literature in which researchers have studied the role of option-implied volatility and skewness in asset pricing, particularly with respect to equity markets (Ang et al., 2006, 2009; Chang et al., 2013; Conrad et al., 2013). More recently, similar techniques have been applied to FX markets (Chen and Gwati, 2014; Jurek, 2014).
} 
where we observe the return, RNV innovations, and RNS innovations for each market.

Our analysis proceeds in two parts. First, we establish a benchmark by evaluating the connectedness among currencies over the full sample period, from January 1999 to October 2014. This reveals significant spillovers among returns, with particularly strong bilateral spillovers among currencies that share an underlying linkage (e.g., the European currencies as well as the commodity currencies). Spillovers of RNV innovations across currencies exert a strong influence over the evolution of volatility in each market, accounting for as much as $75 \%$ of the ten-days-ahead forecast error variance of RNV innovations. By contrast, currency-specific or idiosyncratic factors strongly influence the behavior of RNS innovations, reflecting the importance of market-specific shocks in driving the risk of large jumps or crashes in exchange rates.

Next, we analyze time variation in the pattern and intensity of spillovers using rolling samples of 250 trading days. This reveals that aggregate spillover intensity is inversely related to the federal funds rate, indicating that spillovers strengthen (weaken) as economic and financial conditions in the U.S. deteriorate (improve). Similarly, spillovers intensify during periods of illiquidity (captured via the TED spread) and periods of uncertainty in equity markets (represented by the VIX). Adverse shocks — particularly the GFC and the European sovereign debt crisis - are associated with a marked increase in spillover intensity. Spillovers from RNV and RNS innovations to realized returns pick up substantially during the crises as investors strive to manage their risk exposure through portfolio rebalancing. Cross-market skewness spillovers intensify particularly markedly at this time, reflecting a sharp increase in coordinated crash risk, a finding that reflects the well-documented liquidity constraints that emerged during the crises.

Our paper is a logical development of the literature on volatility spillovers initiated by Engle, Ito, and Lin (1990). Among the early papers in this literature, Kearney and Patton (2000) and Hong (2001) use GARCH-type models to construct latent measures of volatility. More recently, the focus has shifted towards the use of high-frequency realized 
volatility measures (e.g., Melvin and Melvin, 2003; Cai, Howorka, and Wongswan, 2008; Bubák, Kočenda, and Žikeš, 2011). We are aware of just one study that uses option-implied volatilities. Nikkinen, Sahlström, and Vähämaa (2006) work with option-implied volatilities derived from the Garman and Kohlhagen (1983) model to study volatility transmission in three currency pairs using just two years of data. Network models have not been employed within this literature, nor has there been any attempt to account for the interaction of returns with higher-order moments. Consequently, our work significantly extends the frontier of the existing literature.

This paper proceeds as follows. In Section 2, we outline the methodology. In Section 3, we discuss the dataset, including the computation of the moments of the risk-neutral distribution of expected exchange rate changes. In Sections 4-6, we present the main findings and several robustness exercises. We conclude in Section 7. Additional details are provided in an online technical supplement.

\section{Methodology}

In this section, we describe our empirical network model. First, we specify a vector autoregression as an approximating model for the system. Second, we show how this model can be used to measure connectedness. Third, we demonstrate how this approach can be generalized to analyze connectedness among groups of variables.

\subsection{The model}

We consider the bilateral spot exchange rates for $i=1,2, \ldots, N$ currencies measured in units of U.S. dollars per foreign currency unit at daily frequency over $t=1,2, \ldots, T$ trading days. The daily return for each exchange rate is defined as the log difference of the spot rate. For each currency, we observe the daily return, $r_{i t}$, the innovation in risk-neutral volatility, $v_{i t}$, and the innovation in risk-neutral skewness, $s_{i t}$. Section 3 contains more information on the construction of these variables. The $3 \times 1$ vector $\boldsymbol{y}_{i t}=\left(r_{i t}, v_{i t}, s_{i t}\right)^{\prime}$ collects the market- 
specific variables for the $i$-th market and the $3 N \times 1$ vector $\boldsymbol{y}_{t}=\left(\boldsymbol{y}_{1 t}^{\prime}, \boldsymbol{y}_{2 t}^{\prime}, \ldots, \boldsymbol{y}_{N t}^{\prime}\right)^{\prime}$ contains all variables for every market. The total number of variables in the system is $d=3 N$.

Given our opening premise that ongoing rebalancing activity leads to complex feedback effects within and between FX markets, we require an approximating model that allows all variables to be endogenously determined. A finite order vector autoregression (VAR) is a leading candidate (Diebold and Yilmaz, 2014). Abstracting from deterministic terms for clarity of exposition, the $p$-th order reduced-form VAR for the $d \times 1$ vector of variables $\boldsymbol{y}_{t}$ is as follows:

$$
\boldsymbol{y}_{t}=\sum_{j=1}^{p} \boldsymbol{A}_{j} \boldsymbol{y}_{t-j}+\boldsymbol{u}_{t}
$$

where the $\boldsymbol{A}_{j}$ for $j=1, \ldots, p$ are $d \times d$ coefficient matrices and $\boldsymbol{u}_{t} \sim N\left(\mathbf{0}, \boldsymbol{\Sigma}_{u}\right)$ contains the reduced-form residuals, which have covariance matrix $\boldsymbol{\Sigma}_{u}$. Pesaran and Shin (1998) show that the $h$-step-ahead generalized forecast error variance decomposition (GVD) for the $i$-th variable is given by:

$$
\vartheta_{i \leftarrow j}^{(h)}=\frac{\sigma_{u, j j}^{-1} \sum_{\ell=0}^{h-1}\left(\boldsymbol{\epsilon}_{i}^{\prime} \boldsymbol{B}_{\ell} \boldsymbol{\Sigma}_{u} \boldsymbol{\epsilon}_{j}\right)^{2}}{\sum_{\ell=0}^{h-1} \boldsymbol{\epsilon}_{i}^{\prime} \boldsymbol{B}_{\ell} \boldsymbol{\Sigma}_{u} \boldsymbol{B}_{\ell}^{\prime} \boldsymbol{\epsilon}_{i}}
$$

for $i, j=1, \ldots, d$, where $\sigma_{u, j j}$ is the $j$ th diagonal element of $\boldsymbol{\Sigma}_{u}, \boldsymbol{\epsilon}_{i}$ is a $d \times 1$ selection vector with its $i$-th element set to unity and zeros elsewhere, and where the $\boldsymbol{B}_{\ell}$ coefficient matrices of the infinite order moving average representation of the VAR are defined recursively as $\boldsymbol{B}_{\ell}=\boldsymbol{A}_{1} \boldsymbol{B}_{\ell-1}+\boldsymbol{A}_{2} \boldsymbol{B}_{\ell-2}+\ldots$ for $\ell=1,2, \ldots$ with $\boldsymbol{B}_{0}=\boldsymbol{I}_{d}$ and $\boldsymbol{B}_{\ell}=\mathbf{0}$ for $\ell<0$. $\vartheta_{i \leftarrow j}^{(h)}$ expresses the proportion of the $h$-step-ahead forecast error variance (FEV) of variable $i$, which can be attributed to shocks in the equation for variable $j$. GVDs have the benefit of order invariance, although it will generally be the case that $\sum_{j=1}^{d} \vartheta_{i \leftarrow j}^{(h)}>1$ due to the non-zero correlation between reduced-form shocks. Following Diebold and Yilmaz (2014), the percentage interpretation of the FEV shares can be restored by normalizing such that $\theta_{i \leftarrow j}^{(h)}=100 \times\left(\vartheta_{i \leftarrow j}^{(h)} / \sum_{j=1}^{d} \vartheta_{i \leftarrow j}^{(h)}\right) \%$. 


\subsection{Measuring connectedness using VAR models}

Our goal in developing a network model is to estimate an adjacency matrix summarizing the linkages (edges) among nodes in the network. The adjacency matrix for a $d$-variable system is a $d \times d$ matrix $\boldsymbol{C}$ whose $(i, j)$-th element, $c_{i j}$, is non-zero only if there is a linkage from node $j$ to node $i$. Ex ante, it is reasonable to believe that each FX market is connected to every other and that each element of $\boldsymbol{C}$ will be non-zero. Consequently, our task is to estimate the strength (weight) of each linkage in the network. Also, with no reason to presume that linkages among FX markets are symmetric, we must estimate a directed network, in which $\boldsymbol{C}$ is allowed to be asymmetric.

An elegant framework to estimate an adjacency matrix for a weighted directed network has been proposed by Diebold and Yilmaz (2009, 2014). Their key innovation is to estimate the adjacency matrix - also known as the connectedness matrix - using forecast error variance decompositions applied to an underlying VAR model. They construct the $h$-stepahead $d \times d$ connectedness matrix among the $d$ variables in $\boldsymbol{y}_{t}$ as follows:

$$
\mathbb{C}^{(h)}=\left[\begin{array}{cccc}
\theta_{1 \leftarrow 1}^{(h)} & \theta_{1 \leftarrow 2}^{(h)} & \cdots & \theta_{1 \leftarrow d}^{(h)} \\
\theta_{2 \leftarrow 1}^{(h)} & \theta_{2 \leftarrow 2}^{(h)} & \cdots & \theta_{2 \leftarrow d}^{(h)} \\
\vdots & \vdots & \ddots & \vdots \\
\theta_{d \leftarrow 1}^{(h)} & \theta_{d \leftarrow 2}^{(h)} & \cdots & \theta_{d \leftarrow d}^{(h)}
\end{array}\right]
$$

Diebold and Yilmaz show that $\theta_{i \leftarrow j}^{(h)}$ measures the pairwise spillover from variable $j$ to variable $i$. Furthermore - and importantly in our context - this is a directional measure because it will generally be the case that $\theta_{i \leftarrow j}^{(h)} \neq \theta_{j \leftarrow i}^{(h)}$. We now define the following:

$$
O_{i \leftarrow i}^{(h)}=\theta_{i \leftarrow i}^{(h)} \quad ; \quad F_{i \leftarrow \bullet}^{(h)}=\sum_{j=1, j \neq i}^{d} \theta_{i \leftarrow j}^{(h)} \text { and } T_{\bullet \leftarrow i}^{(h)}=\sum_{j=1, j \neq i}^{d} \theta_{j \leftarrow i}^{(h)} .
$$

The proportion of the $h$-step-ahead FEV of the $i$-th variable that can be attributed to shocks 
to variable $i$ itself is known as the own variance share, $O_{i \leftarrow i}^{(h)}$. The total spillovers from the system to variable $i$ are given by $F_{i \leftarrow \bullet}^{(h)}$, which is referred to as the from connectedness of variable $i$. Likewise, the total spillovers from variable $i$ to the system are measured by $T_{\bullet \leftarrow i}^{(h)}$, which is referred to as the to connectedness of variable $i$. It follows that $O_{i \leftarrow i}^{(h)}+F_{i \leftarrow \bullet}^{(h)}=100 \%$ by construction but that $T_{\bullet \leftarrow i}^{(h)}$ may exceed $100 \%$. Finally, we define the following aggregate summary measures:

$$
S^{(h)}=\frac{1}{d} \sum_{i=1}^{d} F_{i \leftarrow \bullet}^{(h)} \quad \text { and } \quad H^{(h)}=100-S^{(h)}
$$

where $S^{(h)}$ denotes the aggregate spillover index and $H^{(h)}$ is the aggregate own-variable effect.

\subsection{Block aggregation of the connectedness matrix}

The Diebold-Yilmaz framework can be used either to measure spillovers among individual variables or to summarize aggregate spillover activity among all variables in the system. However, it does not provide a simple way to measure spillovers among groups of variables. As such, it is not straightforward to measure spillovers among multiple markets, each of which is represented by three variables: $r_{i t}, v_{i t}$, and $s_{i t}$. Consequently, GreenwoodNimmo et al. (2015a) develop a generalized framework that exploits block aggregation of the connectedness matrix. Block aggregation introduces a new stratum between the level of individual variables and the system-wide aggregate level, thereby enhancing the flexibility of the Diebold-Yilmaz framework.

Suppose that the variables are in the order $\boldsymbol{y}_{t}=\left(r_{1 t}, v_{1 t}, s_{1 t}, r_{2 t}, v_{2 t}, s_{2 t}, \ldots, r_{N t}, v_{N t}, s_{N t}\right)^{\prime}$ and that we wish to evaluate the connectedness among the $N$ markets in the model in a combined manner that encompasses all three variables in each market. We can write the connectedness matrix $\mathbb{C}^{(h)}$ in block form with $g=N$ groups each composed of $m=3$ 
variables as follows:

$$
\mathbb{C}^{(h)}=\left[\begin{array}{cccc}
\mathbf{B}_{1 \leftarrow 1}^{(h)} & \mathbf{B}_{1 \leftarrow 2}^{(h)} & \ldots & \mathbf{B}_{1 \leftarrow N}^{(h)} \\
\mathbf{B}_{2 \leftarrow 1}^{(h)} & \mathbf{B}_{2 \leftarrow 2}^{(h)} & \ldots & \mathbf{B}_{2 \leftarrow N}^{(h)} \\
\vdots & \vdots & \ddots & \vdots \\
\mathbf{B}_{N \leftarrow 1}^{(h)} & \mathbf{B}_{N \leftarrow 2}^{(h)} & \ldots & \mathbf{B}_{N \leftarrow N}^{(h)}
\end{array}\right], \mathbf{B}_{i \leftarrow j}^{(h)}=\left[\begin{array}{ccc}
\theta_{r_{i} \leftarrow r_{j}}^{(h)} & \theta_{r_{i} \leftarrow v_{j}}^{(h)} & \theta_{r_{i} \leftarrow s_{j}}^{(h)} \\
\theta_{v_{i} \leftarrow r_{j}}^{(h)} & \theta_{v_{i} \leftarrow v_{j}}^{(h)} & \theta_{v_{i} \leftarrow s_{j}}^{(h)} \\
\theta_{s_{i} \leftarrow r_{j}}^{(h)} & \theta_{s_{i} \leftarrow v_{j}}^{(h)} & \theta_{s_{i} \leftarrow s_{j}}^{(h)}
\end{array}\right]
$$

for $i, j=1,2, \ldots, N$ and where the block $\mathbf{B}_{i \leftarrow i}^{(h)}$ collects all the within-market effects for market $i$ while $\mathbf{B}_{i \leftarrow j}^{(h)}$ collects all spillover effects from market $j$ to market $i$. GreenwoodNimmo et al. (2015a) stress that, due to the order-invariance of GVDs, the variables in $\boldsymbol{y}_{t}$ can be re-ordered as necessary to support any desired block structure. ${ }^{4}$ Using (6), we can define the total within-market FEV contribution for market $i$ as follows:

$$
\mathcal{W}_{i \leftarrow i}^{(h)}=\frac{1}{m} \mathbf{e}_{m}^{\prime} \mathbf{B}_{i \leftarrow i}^{(h)} \mathbf{e}_{m}
$$

where $\mathbf{e}_{m}$ is an $m \times 1$ vector of ones. As such, $\mathcal{W}_{i \leftarrow i}^{(h)}$ measures the proportion of the $h$-stepahead FEV of $\mathbf{y}_{i t}$ due to shocks to $\mathbf{y}_{i t} . \mathcal{W}_{i \leftarrow i}^{(h)}$, can be decomposed into common-variable FEV contributions within market $i, \mathcal{O}_{i \leftarrow i}^{(h)}$, and cross-variable effects, $\mathcal{C}_{i \leftarrow i}^{(h)}$, as follows:

$$
\mathcal{O}_{i \leftarrow i}^{(h)}=\frac{1}{m} \operatorname{trace}\left(\mathbf{B}_{i \leftarrow i}^{(h)}\right) \text { and } \mathcal{C}_{i \leftarrow i}^{(h)}=\mathcal{W}_{i \leftarrow i}^{(h)}-\mathcal{O}_{i \leftarrow i}^{(h)}
$$

Note that $\mathcal{O}_{i \leftarrow i}^{(h)}$ measures the proportion of the $h$-step-ahead FEV of $\mathbf{y}_{i t}$ that is not attributable to spillovers among the variables within market $i$ nor to spillovers from other

\footnotetext{
${ }^{4}$ To provide a clear and concise exposition, the derivation of the block aggregation routine presented here focuses on connectedness among markets. This is the case that we consider in Table 2 and Figure 3. We also present results in Table 3 and Figure 4 for the connectedness among groups of common moments (i.e. returns for all markets, RNV innovations for all markets, and RNS innovations for all markets). It is straightforward to adapt the method presented here to evaluate the connectedness among groups of common moments. One first reorders the variables in the VAR to obtain $\mathbf{y}_{t}=\left(\mathbf{r}_{t}, \mathbf{v}_{t}, \mathbf{s}_{t}\right)^{\prime}$, where $\mathbf{r}_{t}=\left(r_{1 t}, r_{2 t}, \ldots, r_{N t}\right)$, $\mathbf{v}_{t}=\left(v_{1 t}, v_{2 t}, \ldots, v_{N t}\right)$, and $\mathbf{s}_{t}=\left(s_{1 t}, s_{2 t}, \ldots, s_{N t}\right)$, and then aggregates into $g=3$ groups of common moments, each of which is composed of $m=N$ variables. The block structure used in this case is detailed in the online technical supplement.
} 
markets to market $i$. By contrast, $\mathcal{C}_{i \leftarrow i}^{(h)}$ records the total $h$-step-ahead spillovers between the return, RNV innovation, and RNS innovation within market $i$. The total pairwise directional spillovers from market $j$ to market $i$ at horizon $h$ are given by:

$$
\mathcal{F}_{i \leftarrow j}^{(h)}=\frac{1}{m} \mathbf{e}_{m}^{\prime} \mathbf{B}_{i \leftarrow j}^{(h)} \mathbf{e}_{m}
$$

while the aggregate from and to connectedness of market $i$ are given by:

$$
\mathcal{F}_{i \leftarrow \bullet}^{(h)}=\sum_{j=1, j \neq i}^{N} \mathcal{F}_{i \leftarrow j}^{(h)} \text { and } \mathcal{T}_{\bullet \leftarrow i}^{(h)}=\sum_{j=1, j \neq i}^{N} \mathcal{F}_{j \leftarrow i}^{(h)},
$$

respectively. Finally, the aggregate between-market spillover measure and the aggregate within-market effect are:

$$
\mathcal{S}^{(h)}=\frac{1}{N} \sum_{i=1}^{N} \mathcal{F}_{i \leftarrow \bullet}^{(h)} \text { and } \mathcal{H}^{(h)}=100-\mathcal{S}^{(h)} .
$$

The interpretation of each of these quantities follows easily from the discussion of the Diebold-Yilmaz method in Section 2.2.

\section{Dataset and risk-neutral moments}

Our model is estimated using daily returns and the innovations in RNV and RNS for the G10 currencies, with all quotes against the U.S. dollar. ${ }^{5}$ We therefore work with the following nine currencies: the Australian dollar (AUD), the British pound (GBP), the Canadian dollar (CAD), the euro (EUR), the Japanese yen (JPY), the New Zealand dollar (NZD), the Norwegian krone (NOK), the Swedish krona (SEK), and the Swiss franc (CHF). Our sample spans the period since the introduction of the euro, from January 1999 to October 2014.

\footnotetext{
${ }^{5}$ We also consider a model including innovations in risk-neutral kurtosis (RNK) but find this to yield little empirical benefit, as demonstrated in the online technical supplement. RNK is also found to be relatively unimportant in an empirical sense by Rafferty (2012). In general, to the extent that investors are concerned about mass in the tails of the expected distribution of future exchange rate changes, their preferences will tend to be strongly asymmetric and this will be captured by the RNS.
} 
We compute the daily return for the $i$-th currency using data on the spot exchange rate, which is sourced from WM/Reuters via Datastream. We compute the risk-neutral moments following the model-free framework developed by Bakshi and Madan (2000), Carr and Madan (2001), and Bakshi et al. (2003) and applied to foreign exchange options by Jurek (2014). The computation requires appropriate forward exchange rate data, an annualized domestic interest rate, and a set of at-the-money and out-of-the-money call and put options. We gather daily one-month forward exchange rate data for each currency quoted against the U.S. dollar from WM/Reuters via Datastream. For the interest rate, we use daily data on U.S. eurocurrency interbank money market interest rates with a maturity of one month collected from the Financial Times and ICAP via Datastream. Finally, daily quotes for over-the-counter European FX options with a maturity of one month are provided by J.P. Morgan. The options data are quoted in the form of implied volatilities for portfolios of out-of-the-money $25 \delta$ and $10 \delta$ options contracts, as well as an at-the-money delta-neutral $(0 \delta)$ straddle. From these, we extract the relevant strike prices and options prices using the Garman and Kohlhagen (1983) formulae. Using these, we then compute the model-free risk-neutral moments. Further details of the computation of the risk-neutral moments are in the online technical supplement.

Following the approach adopted by Menkhoff et al. (2012) and Chang et al. (2013), we work with the innovations in RNV and RNS rather than their levels. The RNV innovations for the $i$-th market, $v_{i t}$, are extracted as the residuals from the following auxiliary first order autoregression:

$$
v_{i t}=\mathrm{VOL}_{i t}^{R N}-\widehat{\phi}_{i v} \mathrm{VOL}_{i, t-1}^{R N}-\widehat{\mu}_{i v}
$$

where $\operatorname{VOL}_{i t}^{R N}$ denotes the option-implied risk-neutral volatility for currency $i$ at time $t$ and where Greek letters denote the estimated model parameters. We compute the RNS innovations, $s_{i t}$, in the same manner. The use of innovations confers two benefits. First, it allows us to account for the serial correlation in the risk-neutral moments without including 
a large number of lags in our VAR model. This allows us to work with shorter rolling samples and, thereby, to achieve richer patterns of time variation. Second, it allows us to focus on unexpected changes in RNV and RNS, which reflect unexpected changes in the investment opportunity set facing investors.

\section{Full-sample analysis}

\subsection{Connectedness among variables over the full sample}

To establish a point of reference, we first study connectedness over the full sample. We estimate a $\operatorname{VAR}(1)$ model, where the VAR lag length is selected using the Schwarz criterion. In order to compute the connectedness matrix in (3), one must first choose an appropriate forecast horizon. However, as there is no simple method to select an optimal horizon, we experiment with $h \in\{5,10,15\}$ trading days, a range that encompasses the values used in most existing applications of the Diebold-Yilmaz framework to daily data. In practice, the connectedness matrix is highly robust to the choice of forecast horizon. The Frobenius norms for $\mathbb{C}^{(5)}, \mathbb{C}^{(10)}$, and $\mathbb{C}^{(15)}$ are $277.118,277.117$, and 277.117 , respectively, indicating that the three connectedness matrices are almost identical, an observation that is substantiated by an elementwise comparison of the matrices (available on request). We therefore adopt $h=10$ throughout our full-sample analysis without loss of generality. We discuss the issue of robustness in the context of rolling regression analysis in Section 5 .

Table 1 presents the full-sample ten-days-ahead $27 \times 27$ variable connectedness matrix. This matrix fully quantifies the magnitude of all pairwise linkages among individual variables in the network. Own-variable effects are contained along the main diagonal, while offdiagonal elements represent directional spillovers. Several features are noteworthy. Firstly, consider spillovers affecting returns. Given the premise that portfolio rebalancing in response to changes in the risk-return profiles of a set of currencies is an important feature of FX markets, one may expect to see strong cross-market spillovers among returns. This is indeed the case over the full sample and is consistent with currency comovements driven by 
investors rebalancing positions in multiple currencies simultaneously in response to shocks, as documented by Elyasiani and Kocagil (2001), Cai et al. (2008), and Greenwood-Nimmo et al. (2015b).

- Insert Table 1 about here -

Table 1 shows that cross-market spillovers between the returns on different currencies account for more than $50 \%$ of the return FEV in most cases. Own-variable effects, by contrast, typically account for only $20 \%-30 \%$ of the ten-days-ahead FEV. Spillovers among returns are particularly strong where currencies share an underlying linkage. This is especially true of the European currencies, as well as the commodity currencies (AUD, CAD, and NZD). Within these groups, many of the bilateral return spillovers are of the order of $10 \%-15 \%$. Such strong bilateral return spillovers among a subset of currencies suggests a degree of common rebalancing activity affecting these currencies. For example, investors may elect to simultaneously reduce their exposure to the entire set of commodity currencies in the event of an adverse shock to commodity prices.

While cross-market spillovers between returns dominate for most currencies, the JPY emerges as a notable special case. Cross-market return spillovers from other currencies account for a mere $14 \%$ of the JPY return FEV. By contrast, the own-variable effect for JPY returns is $52 \%$, which is considerably stronger than in any other currency market. The relative disconnect of JPY returns from the returns of other currencies strongly supports the notion that the JPY is a safe haven currency (Ranaldo and Söderlind, 2010).

In the case of RNV innovations, the literature on volatility transmission furnishes a strong prior expectation — volatility has been repeatedly shown to spread rapidly and forcefully among FX markets (e.g., Engle et al., 1990; Fleming et al., 1998). This is readily apparent in Table 1. Own-variable effects for RNV innovations account for between $17 \%$ (EUR) and $27 \%$ (JPY) of the ten-days-ahead FEV, with an average value of $20 \%$. By contrast, spillovers between RNV innovations across currencies are much stronger, ranging from $59 \%$ (JPY) to 
$77 \%$ (EUR), a finding that is also consistent with the role of a global FX volatility factor in driving the RNV innovations of individual currencies (Menkhoff et al., 2012). As with return spillovers, strong bilateral volatility spillovers are evident between currencies that share an underlying linkage. For the commodity currencies, common exposure to commodity price volatility provides an appealing explanation for this phenomenon. Meanwhile, among the European currencies, joint exposure to common sources of uncertainty (e.g., related to geopolitical linkages) is likely to play an important role. Lastly, the safe haven status of the JPY is again apparent, as the JPY is considerably less susceptible to cross-market RNV spillovers than other currencies.

From Table 1, it is clear that RNS innovations experience considerably stronger ownvariable effects than either returns or RNV innovations and, by construction, commensurately weaker spillovers from the system. There is marked heterogeneity across markets, with the own-variable effects for RNS innovations varying in the range $64 \%$ (NZD) to $91 \%$ (CAD) and taking an average value of $76 \%$. Currencies' upside and downside crash risks are more strongly influenced by currency-specific idiosyncratic shocks than is the case for either returns or RNV innovations. This is in line with the limited literature on skewness spillovers in equity markets, which emphasizes the role of local factors (Hashmi and Tay, 2007, 2012). Nevertheless, more closely related currency pairs exhibit stronger bilateral skewness spillovers (e.g., the NOK-SEK and AUD-NZD pairs), which suggests that exposure to common shocks may induce a degree of common crash risk.

\subsection{Connectedness among markets and among moments over the full sample}

Over the full sample, it is possible to meaningfully interpret the 729 elements of the $27 \times 27$ variable connectedness matrix shown in Table 1 . However, this rapidly becomes burdensome when working with subsamples and is wholly infeasible in the context of rolling regression analysis. As noted above, block aggregations of the connectedness matrix can be used to focus the analysis as desired and measure spillovers among groups of variables. We 
outline two cases here, both of which are employed in the rolling-sample analysis below.

Table 2 presents the $9 \times 9$ market connectedness matrix, which contains total withinmarket effects for each currency along the prime diagonal and total directional spillovers between currency market pairs in the off-diagonal entries. Adopting the nomenclature proposed by Engle et al. (1990), the within-market effects can be thought of as heatwave effects while the cross-market spillovers are akin to meteor showers. Presenting the market connectedness matrix in this way highlights the key interactions among markets. In the majority of markets, the heatwave effect accounts for less than $50 \%$ of the FEV and spillovers from other markets typically exert a dominant influence. Currencies that share an underlying linkage experience stronger bilateral spillovers. The safe haven status of the JPY is reflected in the strong within-market effect and relatively low cross-market spillovers.

- Insert Table 2 about here -

Table 3 reports the $3 \times 3$ moment connectedness matrix, which measures the full-sample connectedness among groups of returns, RNV innovations, and RNS innovations, aggregated over all 9 markets. In this case, within-moment effects are recorded along the prime diagonal, with spillovers across moments occupying the off-diagonal positions. This representation of the connectedness matrix focuses attention specifically on interactions between returns and innovations in RNV and RNS. This allows for a clear characterization of risk spillovers onto returns (as investors rebalance their portfolios in response to changes in risk) and also of return spillovers onto risk measures (as rebalancing activity and changes in returns feed back onto the risk measures).

— Insert Table 3 about here —

Close inspection of Table 3 reveals that interactions among variables of the same type (e.g., interactions among returns or interactions among RNV innovations) are by far the dominant force in the system over the full sample, accounting for more than $80 \%$ of FEV in 
each case. Nonetheless, spillovers between returns, RNV innovations, and RNS innovations are non-negligible, implying that there exists a bidirectional relation where returns adjust in response to innovations in the option-implied moments and vice versa. However, as stressed by Diebold and Yilmaz (2014), the full-sample connectedness measures only characterize unconditional linkages over the full sample. In practice, it is likely that the linkages between returns and changes in risk will vary over time, particularly to the extent that currency risk premia are countercyclical (Lustig, Roussanov, and Verdelhan, 2014). Such issues can be analyzed using rolling regression to construct conditional connectedness measures.

\section{Rolling-sample analysis}

Window length is an important choice in the context of rolling regressions. Applications of the Diebold-Yilmaz method based on daily data have used a range of values - for example, the main results in Diebold and Yilmaz (2014) are based on $w=100$ days while Baruník et al. (2016) use $w=200$ days. Given this uncertainty, the emergent norm in the literature is to evaluate the sensitivity of the rolling connectedness measures to several candidate window lengths. Adopting this approach, we consider candidate values in the set $w \in\{200,250,300\}$ trading days. Furthermore, we consider candidate forecast horizons in the set $h \in\{5,10,15\}$ trading days to verify that the robustness of our full-sample results to the choice of forecast horizon also extends to rolling-sample analysis. Lastly, for completeness, we investigate the effect of adopting Diebold and Yilmaz's (2009) earlier approach to measuring connectedness, which employs orthogonalized forecast error variance decompositions (OVDs) rather than GVDs. Consequently, the design of our sensitivity analysis closely follows that of Diebold and Yilmaz (2014, section 5.3.4). ${ }^{6}$

Figure 1 reveals that neither the choice of forecast horizon nor of window length exerts a major influence on our results. The time series behavior of the aggregate spillover index

\footnotetext{
${ }^{6}$ Unlike many existing applications of the Diebold-Yilmaz approach, which simply impose the same VAR lag length in every rolling sample, we select the lag length for the $r$-th rolling regression from the set $p_{r} \in\{1,2, \ldots, 5\}$ using the Schwarz criterion. In practice, $\operatorname{VAR}(1)$ is selected in every rolling sample.
} 
defined in (5) is remarkably similar in all cases. Furthermore, the correlation between the spillover indices based on GVDs and the mean of the spillover indices based on OVDs under 1,000 random variable orderings is no lower than 0.95 in any case, although there is a slight level shift separating the two sets of results. Diebold and Yilmaz (2014, p. 130) observe the same effect and note that the aggregate spillover activity computed using OVDs acts as a lower bound on that derived from GVDs. Overall, the GVD results can be considered more accurate because they accommodate the full correlation structure of the reduced-form VAR disturbances.

\section{— Insert Figure 1 about here -}

\subsection{Aggregate spillover activity over time}

In light of Figure 1, the remainder of our analysis focuses on the GVD case with $w=250$ trading days and $h=10$ trading days without loss of generality. This case corresponds to the central panel of Figure 1. Figure 2 shows the aggregate spillover index in this case, enlarged and annotated with the timing of several major events. The figure reveals substantial time variation. Spillovers begin to rise in late 2000 following the collapse of the dot-com bubble and the ensuing U.S. recession. They continue to rise during the Federal Reserve's monetary accommodation from 2001 to 2004. Spillover activity then gradually recedes with the normalization of U.S. interest rates until the onset of the subprime mortgage crisis in 2007, with a particularly rapid intensification of spillover activity following the collapse of Lehman Brothers in September 2008. Spillovers remain at a high level during the GFC and for several years thereafter during the European sovereign debt crisis before receding in late 2012 with the gradual abatement of the debt crisis.

\section{— Insert Figure 2 about here -}

\subsection{Connectedness among markets over time}

In Figure 3, we summarize the time-varying connectedness among markets. Working at this level of aggregation allows us to identify which currency markets are more (or less) 
integrated and how this changes over time. The figure is composed of nine panels, one for each market. The panel for the $i$-th market contains an upper plot showing the within-market heatwave effect, $\mathcal{W}_{i \leftarrow i}^{(10)}$ and a lower plot showing the total inward and outward spillovers for market $i, \mathcal{F}_{i \leftarrow \bullet}^{(10)}$ and $\mathcal{T}_{\bullet \leftarrow i}^{(10)}$, respectively.

\section{— Insert Figure 3 about here -}

Consider the top row of Figure 3, which contains the commodity currencies (AUD, NZD, and CAD). In each case, the within-market effect is very high at the start of the sample (approximately $70 \%$ of market FEV), indicating strong idiosyncratic variation and relatively weak integration with the other markets in the system. However, this changes markedly over the sample period, dropping to around 30\% during the GFC. Between-market spillover activity - both inward and outward - increases markedly at this time, reflecting much greater integration of the commodity currencies with the system as a whole. Greater integration of commodity currencies is likely to reflect the marked financialization of commodity markets during our sample period (Cheng and Xiong, 2014).

The European currencies (EUR, NOK, and SEK) appear on the middle row. Along with the $\mathrm{CHF}$, this group displays markedly common behavior, with low within-market (idiosyncratic) effects throughout the sample matched by strong between-market spillovers. This indicates that the European currencies are closely integrated, while the positive net spillovers arising from the EUR and the CHF over much of the sample suggest that these are the leading markets within the group, as one would expect. ${ }^{7}$ Finally, the JPY and, to a lesser extent, the GBP exhibit somewhat more idiosyncratic variation than the other currencies, which is matched by weak between-market spillovers. These two currencies are relatively weakly integrated with the other markets, indicating that they may offer a safe haven to FX investors. This is true of the GBP early in the sample and of the JPY throughout the sample.

\footnotetext{
${ }^{7}$ The ten-days-ahead net connectedness of the $i$-th market is defined as $\mathcal{N}_{i}^{(10)}=\mathcal{T}_{\bullet \leftarrow i}^{(10)}-\mathcal{F}_{i \leftarrow \bullet}^{(10)}$.
} 


\subsection{Connectedness among moments over time}

Figure 4 shows the evolution of connectedness among moments over rolling samples. The figure contains nine panels, each of which contains two plots. The upper plot shows the connectedness among moments within the same market and the lower plot shows the connectedness among moments between markets. ${ }^{8}$ Consequently, Figure 4 enables us to investigate the relative importance over time of idiosyncratic currency-specific effects and of systematic cross-market spillovers affecting returns, RNV innovations, and RNS innovations, respectively. It also allows us to investigate changes in the interaction between returns and innovations in RNV and RNS over time. As mentioned above, the countercyclical currency risk premia described by Lustig et al. (2014) are likely to result in stronger interactions between returns and innovations in RNV and RNS in bad times over the business cycle as returns become more sensitive to changes in risk and vice versa.

— Insert Figure 4 about here -

The top row of Figure 4 reports the evolution of the spillovers affecting returns over our sample period. As with the full-sample results documented above, the own-variable within-market effect in returns is relatively weak, always remaining below $40 \%$ and declining substantially during the GFC. Spillovers among returns between markets are much stronger in general, peaking at $68 \%$ in 2005 before dipping during the GFC. Meanwhile, spillovers to returns from RNV and RNS innovations increase substantially during the GFC and the European sovereign debt crisis, reaching a combined high of nearly $50 \%$ in October 2008 shortly after the collapse of Lehman Brothers. This is a clear indication of a marked increase in investors' sensitivity to risk during the crises. Furthermore, given that the large majority of spillovers to returns from RNV and RNS innovations occurs between markets,

\footnotetext{
${ }^{8}$ The structure of Figure 4 maps onto the structure of Table 3 except that each element of the table is decomposed into a within-market and a between-market effect using a similar method to that described in (8). Full computational details are provided in the online technical supplement.
} 
one may infer that investors were particularly concerned with systematic risk (aggregate FX uncertainty and crash risk in particular).

In the second row of Figure 4, we focus on spillovers affecting RNV innovations. As with returns, the own-variable within-market effect in RNV innovations is relatively weak and gradually declines across our sample. By contrast, between-market spillovers among RNV innovations have gradually intensified from roughly $50 \%$ at the start of our sample to more than $65 \%$ towards the end of the sample, indicating that systematic volatility linkages dominate the effect of idiosyncratic volatility. In addition, cross-market spillovers from returns to RNV innovations strengthen considerably in the aftermath of the GFC and during the European sovereign debt crisis. Consequently, our results indicate that investors' expectations of future exchange rate volatility are heavily conditioned on realized exchange rate movements and vice versa, at least in times of stress. This is a clear manifestation of the feedback effects between rebalancing activity and risk measures outlined in our opening remarks and it underscores the value of network models in this context.

The last row of Figure 4 reveals that the own-variable within-market effect in RNS innovations (i.e., the idiosyncratic variation in skewness) is much stronger than is the case with either returns or RNV innovations. Furthermore, it displays marked time variation, falling dramatically during the GFC and European debt crisis from $50 \%$ of FEV to less than $25 \%$. This is mirrored by an increase in between-market spillovers among RNS innovations. The intensification of skewness spillovers across markets during turbulent times suggests that coordinated crash risk is more prevalent during times of financial stress, as the likelihood of carry trade positions having to be unwound due to liquidity constraints increases (Brunnermeier et al., 2009; Rafferty, 2012). Finally, we also observe a large increase in spillovers from returns to RNS innovations during the GFC and the European sovereign debt crisis, which indicates that investors' forward-looking perceptions of crash risk are heavily conditioned on realized exchange rate movements, as one may expect. 


\section{Relation to macroeconomic and financial conditions}

Careful consideration of our rolling-sample results suggests two interesting phenomena that may be discerned most easily in relation to the aggregate spillover index in Figure 2. First, it appears that FX spillovers evolve countercyclically. Second, FX spillovers intensify in times of financial stress, most notably during the GFC and the European sovereign debt crisis. Both effects are demonstrated in Figure 5, where we plot the rolling spillover index shown in Figure 2 alongside the 250-day rolling average of the federal funds rate, the TED spread, and the VIX, respectively. The use of rolling averages provides a measure of the low frequency movements of each series, which lends itself to a medium- or long-term interpretation.

\section{- Insert Figure 5 about here -}

The federal funds rate is a gauge of the cyclical position of the U.S. economy. Figure 5 shows a remarkably strong negative relation between aggregate FX spillovers and the federal funds rate, indicating a clear countercyclical pattern. The correlation is -0.54 over the full sample and -0.71 in the period up to December 2008, after which active interest rate policy was curtailed by the zero lower bound (ZLB). This striking correlation is consistent with a U.S. dollar factor driving exchange rate dynamics and linkages in FX markets (Lustig, Roussanov, and Verdelhan, 2011) and is highly suggestive of countercyclical currency risk premia relative to the U.S. dollar (Lustig et al., 2014). One can envisage a number of mechanisms underlying the countercyclicality of aggregate spillover activity. For example, risk-averse investors may become more responsive to changes in the risk environment during downturns, leading to an intensification of spillovers from risk measures to returns. Such a change is also likely to be reflected in the options data due to hedging activity, thereby strengthening spillovers from realized returns to RNV and RNS innovations.

The TED spread is a common proxy for credit risk and funding liquidity in the interbank money market. It is the spread between the three-month U.S. LIBOR and the three-month 
U.S. Treasury bill rate. Mancini, Ranaldo, and Wrampelmeyer (2013) show that when the TED spread increases, market-wide FX liquidity decreases. When the TED spread spikes as it did in the GFC, especially after the collapse of Lehman Brothers — funding liquidity dries up, forcing investors to rapidly unwind their long positions. As described by Rafferty (2012), this is likely to induce coordinated crashes in the FX markets. Consequently, the relation between FX spillover activity and the TED spread is likely to be positive, and strongly so during the GFC. This is exactly what we see in the central panel of Figure 5. Over the full sample, we observe a modest positive correlation of 0.11 , which rises to 0.42 when evaluated over the period since September 2008.

Lastly, the bottom panel of Figure 5 relates to the VIX, which is an option-implied measure of expected volatility for the S\&P 500 that has been widely adopted as a proxy for investors' fear and uncertainty. This figure shows an unambiguous positive correlation between FX spillovers and the VIX. The correlation stands at a moderate 0.33 over the full sample but rises to 0.75 in the period since September 2008. One would expect such a strongly positive correlation if risk-averse investors elect to rebalance their portfolios and adjust their hedging strategies more often and/or more substantially in an uncertain environment. This is consistent with the idea that many investors reduce their exposure to risky assets in periods of elevated uncertainty.

To complement the preceding low frequency analysis, we examine the extent to which large changes in the spillover index occur in conjunction with large changes to the federal funds rate, the TED spread or the VIX. To this end, we construct the following binary indicators to identify periods in which the rolling spillover index, $S_{t}^{(h)}$, reaches a new 250day high or low, respectively:

${\overline{S_{t}}}^{(h)}=\mathbb{1}\left\{S_{t}^{(h)}-\max \left(S_{t-1}^{(h)}, \ldots, S_{t-250}^{(h)}\right)>0\right\} \& \underline{S}_{t}^{(h)}=\mathbb{1}\left\{S_{t}^{(h)}-\min \left(S_{t-1}^{(h)}, \ldots, S_{t-250}^{(h)}\right)<0\right\}$, where $\mathbb{1}\{\cdot\}$ is an indicator function that takes the value one if the condition in braces is 
satisfied and zero otherwise. We apply the same procedure to define 250-day high and low indicator variables for the federal funds rate $\left(\overline{F_{t}}\right.$ and $\left.\underline{F_{t}}\right)$, the TED spread $\left(\overline{T_{t}}\right.$ and $\left.\underline{T_{t}}\right)$, and the VIX $\left(\overline{V_{t}}\right.$ and $\left.\underline{V_{t}}\right)$. We then use these indicators to compute an array of pseudo-hit-rates. For example, the pseudo-hit-rate capturing occasions on which the spillover index records a new 250-day high and the federal funds rate records a new 250-day low within \pm 5 days is given by:

$$
\mathbb{H}\left({\overline{S_{t}}}^{(h)}, \underline{F_{t}}\right)=\left(\frac{\sum_{t=w+1}^{T} \mathbb{1}\left\{\left({\overline{S_{t}}}^{(h)} \times \sum_{i=-5}^{5} \underline{F_{t+i}}\right) \neq 0\right\}}{\sum_{t=w+1}^{T}{\overline{S_{t}}}^{(h)}}\right) \times 100 \% .
$$

In light of Figure 5, given that the spillover index is negatively correlated with the federal funds rate and positively correlated with the TED spread and the VIX, we compute the following pseudo-hit-rates: $\mathbb{H}\left({\overline{S_{t}}}^{(h)}, \underline{F_{t}}\right), \mathbb{H}\left({\underline{S_{t}}}^{(h)}, \overline{F_{t}}\right), \mathbb{H}\left({\overline{S_{t}}}^{(h)}, \overline{T_{t}}\right), \mathbb{H}\left(\underline{S}_{t}^{(h)}, \underline{T_{t}}\right)$, $\mathbb{H}\left({\overline{S_{t}}}^{(h)}, \overline{V_{t}}\right)$, and $\mathbb{H}\left({\underline{S_{t}}}^{(h)}, \underline{V_{t}}\right)$. The results are reported in Table 4, while Figure 6 shows the timing of the respective hits.

— Insert Table 4 and Figure 6 about here -

The hit-rate with respect to the federal funds rate is relatively high over the full sample despite the ZLB constraint, which has seen relative constancy of the effective funds rate since December 2008. When considered only over the pre-ZLB period, the hit rate is quite remarkable, with $62 \%$ of spillover highs occurring within \pm 5 days of a funds rate low and $35 \%$ of spillover lows within \pm 5 days of a funds rate high. Hence, FX market participants appear to respond rapidly to signals arising from U.S. monetary policy, particularly where the signal indicates a deterioration in U.S. macroeconomic and financial conditions. This aligns with the findings of Fischer and Ranaldo (2011), who demonstrate that global FX trading volume increases after Federal Open Market Committee meetings, which is suggestive of increased portfolio rebalancing activity. Figure 6 shows that hits with respect to the federal funds rate occur throughout the pre-ZLB period. Spillover highs are associated with funds rate 
lows during both the Federal Reserve's prolonged monetary accommodation between 2001 and 2003 (related to the U.S. recession following the collapse of the dot-com bubble) and the subsequent monetary easing associated with the GFC. Furthermore, many spillover lows coincide with federal funds rate highs in the period of increasing U.S. interest rates prior to the onset of the subprime mortgage crisis in 2007.

Hit-rates with respect to the TED spread and the VIX are relatively low over the full sample but are much higher in the period of financial turbulence since the collapse of Lehman Brothers in 2008. This is particularly true of the VIX, where almost half of all spillover highs in this period occur within \pm 5 days of a corresponding VIX high and a third of spillover lows correspond to a VIX low, a finding which confirms that FX trading activity is strongly associated with investor sentiment. Furthermore, Figure 6 reveals that large swings in spillover activity may be driven in large part by funding liquidity effects, as hits with respect to the TED spread occur only during periods where the spillover index is either rising or falling dramatically.

\section{Conclusion}

We study the interaction between FX returns and the innovations in the option-implied RNV and RNS for the G10 currencies. Our use of risk-neutral moments accords with recent developments in the literature, which stress their benefits over realized risk measures in terms of their forward-looking nature and their model-free computation (Bakshi and Madan, 2000; Carr and Madan, 2001; Bakshi et al., 2003). Our analysis employs an empirical network model derived from a generalization of the connectedness methodology of Diebold and Yilmaz $(2009,2014)$.

Several interesting results emerge from our analysis. Firstly, over the full sample period, from January 1999 to October 2014, we observe strong spillovers among returns, with particularly notable bilateral spillovers among currencies that share an underlying linkage, such as those that are exposed to common shocks. Similarly, spillovers among RNV inno- 
vations across currencies account for as much as $75 \%$ of the ten-days-ahead FEV of RNV innovations, indicating that systematic volatility plays a dominant role while idiosyncratic volatility is much less important on average. However, over the full sample, the opposite is true of RNS innovations, where idiosyncratic factors play an important role in driving the measured risk of large jumps and crashes in exchange rates.

Rolling-sample analysis reveals significant time variation in both the pattern and intensity of spillovers. A general tendency towards increased spillovers among markets during the GFC and the sovereign debt crisis is apparent. Importantly, we see a large increase in interactions among returns and innovations in risk measures as investors become more responsive to risk during times of financial stress. We also observe increased cross-market connectedness among innovations in RNV and RNS, which implies greater common behavior of forward-looking measures of risk. Spillovers of RNS innovations between markets intensify particularly markedly at this time, highlighting the role of coordinated crash risk during the crises. Finally, we demonstrate that spillover activity among FX markets evolves countercyclically, rising during periods of financial stress and also rising when domestic conditions in the U.S. deteriorate. One can readily envisage mechanisms that may account for these changing patterns of spillover behavior, at least in part. The development of models to formalize such mechanisms represents a fruitful avenue for future research.

\section{Acknowledgements}

We are indebted to J.P. Morgan and to Raphael Brun-Aguerre in particular for providing the FX options data used to compute the risk-neutral moments. We have benefited from constructive discussions with Heather Anderson, Alessio Bonato, Efrem Castelnuovo, Yu-chin Chen, Vance Martin, Anella Munro, Chris Neely, Kalvinder Shields, Yongcheol Shin, and Chris Skeels and from the comments of participants at the First Conference on Recent Developments in Financial Econometrics and Applications (Deakin University, December 2014) and at a research seminar at the University of Auckland. Financial support from the Faculty of Business and Economics at the University of Melbourne is gratefully acknowledged. The usual disclaimer applies. 


\section{References}

Ang, A., Hodrick, R. J., Xing, Y., Zhang, X., 2006. The Cross-Section of Volatility and Expected Returns. Journal of Finance 61, 259-299.

Ang, A., Hodrick, R. J., Xing, Y., Zhang, X., 2009. High Idiosyncratic Volatility and Low Returns: International and Further US Evidence. Journal of Financial Economics 91, 1-23.

Bakshi, G., Kapadia, N., Madan, D., 2003. Stock Return Characteristics, Skew Laws and the Differential Pricing of Individual Equity Options. Review of Financial Studies 16, 101-143.

Bakshi, G., Madan, D., 2000. Spanning and Derivative-Security Valuation. Journal of Financial Economics $55,205-238$.

Bakshi, G., Panayotov, G., 2013. Predictability of Currency Carry Trades and Asset Pricing Implications. Journal of Financial Economics 110 (1), 139-163.

Baruník, J., Kočenda, E., Vácha, L., 2016. Asymmetric Connectedness on the U.S. Stock Market: Bad and Good Volatility Spillovers. Journal of Financial Markets 27, 55-78.

Billio, M., Getmansky, M., Lo, A., Pelizzon, L., 2012. Econometric Measures of Connectedness and Systemic Risk in the Finance and Insurance Sectors. Journal of Financial Economics 104, 535-559.

Brunnermeier, M. K., Nagel, S., Pedersen, L. H., 2009. Carry Trades and Currency Crashes. NBER Macroeconomics Annual 2008 23, 313-347.

Bubák, V., Kočenda, E., Žikeš, F., 2011. Volatility Transmission in Emerging European Foreign Exchange Markets. Journal of Banking and Finance 35, 2829-2841.

Burnside, C., Eichenbaum, M., Kleshchelski, I., Rebelo, S., 2011. Do Peso Problems Explain the Returns to the Carry Trade? Review of Financial Studies 24, 853-891.

Cai, F., Howorka, E., Wongswan, J., 2008. Informational Linkage Across Trading Regions: Evidence from Foreign Exchange Markets. Journal of International Money and Finance 27, 1212-1243.

Carr, P., Madan, D., 2001. Optimal Positioning in Derivative Securities. Quantitative Finance 1, $19-37$.

Chang, B. Y., Christoffersen, P., Jacobs, K., 2013. Market Skewness Risk and the Cross-Section of Stock Returns. Journal of Financial Economics 107, 46-68.

Chen, Y.-C., Gwati, R., 2014. Understanding Exchange Rate Dynamics: What does the Term Structure of FX Options Tell Us? Mimeo, Washington University.

Cheng, I.-H., Xiong, W., 2014. Financialization of Commodity Markets. Annual Review of Financial Economics 6, 419-441.

Christoffersen, P., Jacobs, K., Chang, B. Y., 2013. Forecasting with Option-Implied Information. In: Elliott, G., Timmermann, A. (Eds.), Handbook of Economic Forecasting. Vol. 2A. North-Holland, Amsterdam, pp. $581-656$.

Conrad, J., Dittmar, R. F., Ghysels, E., 2013. Ex Ante Skewness and Expected Stock Returns. The Journal 
of Finance 68, 85-124.

Diebold, F., Yilmaz, K., 2009. Measuring Financial Asset Return and Volatility Spillovers, with Application to Global Equity Markets. Economic Journal 119, 158-171.

Diebold, F., Yilmaz, K., 2014. On the Network Topology of Variance Decompositions: Measuring the Connectedness of Financial Firms. Journal of Econometrics 182, 119-134.

Elyasiani, E., Kocagil, A., 2001. Interdependence and Dynamics in Currency Futures: A Multivariate Cointegration Analysis of Intra-day Data. Journal of Banking and Finance 25, 1161-1186.

Engle, R. F., Ito, T., Lin, W.-L., 1990. Meteor Showers or Heat Waves? Heteroskedastic Intra-daily Volatility in the Foreign Exchange Market. Econometrica 58, 525-524.

Fischer, A. M., Ranaldo, A., 2011. Does FOMC News Increase Global FX Trading? Journal of Banking and Finance 35, 2965-2973.

Fleming, J., Kirby, C., Ostdiek, B., 1998. Information and Volatility Linkages in the Stock, Bond, and Money Markets. Journal of Financial Economics 49, 111-137.

Garman, M. B., Kohlhagen, S. W., 1983. Foreign Currency Option Values. Journal of International Money and Finance 2, 231-237.

Greenwood-Nimmo, M. J., Nguyen, V. H., Shin, Y., 2015a. Measuring the Connectedness of the Global Economy. Mimeo, University of Melbourne.

Greenwood-Nimmo, M. J., Nguyen, V. H., Shin, Y., 2015b. Quantifying Informational Linkages in a Global Model of Currency Spot Markets. Working Paper No. 2443243, SSRN.

Hashmi, A. R., Tay, A. S., 2007. Global Regional Sources of Risk in Equity Markets: Evidence from Factor Models with Time-Varying Conditional Skewness. Journal of International Money and Finance 26, 430453.

Hashmi, A. R., Tay, A. S., 2012. Mean, Volatility and Skewness Spillovers in Equity Markets. In: Bauwens, L., Hafner, C., Laurent, S. (Eds.), Handbook of Volatility Models and Their Applications, 1st Edition. John Wiley and Sons, Ch. 5, pp. 127-145.

Hong, Y., 2001. A Test for Volatility Spillover with Application to Exchange Rates. Journal of Econometrics $103(1), 183-224$.

Jurek, J. W., 2014. Crash-Neutral Currency Carry Trades. Journal of Financial Economics 113, 325-347.

Kearney, C., Patton, A. J., 2000. Multivariate GARCH Modeling of Exchange Rate Volatility Transmission in the European Monetary System. Financial Review 35 (1), 29-48.

Lustig, H., Roussanov, N., Verdelhan, A., 2011. Common Risk Factors in Currency Markets. Review of Financial Studies 24, 3731-3777.

Lustig, H., Roussanov, N., Verdelhan, A., 2014. Countercyclical Currency Risk Premia. Journal of Financial Economics 111, 527-553. 
Mancini, L., Ranaldo, A., Wrampelmeyer, J., 2013. Liquidity in the Foreign Exchange Market: Measurement, Commonality, and Risk Premiums. The Journal of Finance 68, 1805-1841.

Melvin, M., Melvin, B. P., 2003. The Global Transmission of Volatility in the Foreign Exchange Market. Review of Economics and Statistics 85 (3), 670-679.

Menkhoff, L., Sarno, L., Schmeling, M., Schrimpf, A., 2012. Carry Trades and Global Foreign Exchange Volatility. The Journal of Finance 67, 681-718.

Nikkinen, J., Sahlström, P., Vähämaa, S., 2006. Implied Volatility Linkages among Major European Currencies. Journal of International Financial Markets, Institutions and Money 16 (2), 87-103.

Pesaran, M., Shin, Y., 1998. Generalized Impulse Response Analysis in Linear Multivariate Models. Economics Letters 58, 17-29.

Rafferty, B., 2012. Currency Returns, Skewness and Crash Risk. Working Paper 2022920, SSRN.

Ranaldo, A., Söderlind, P., 2010. Safe Haven Currencies. Review of Finance 14, 385-407. 


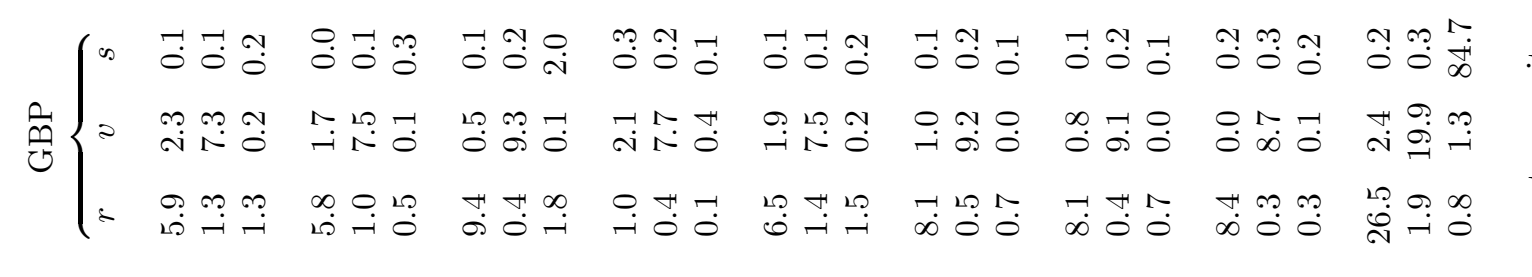

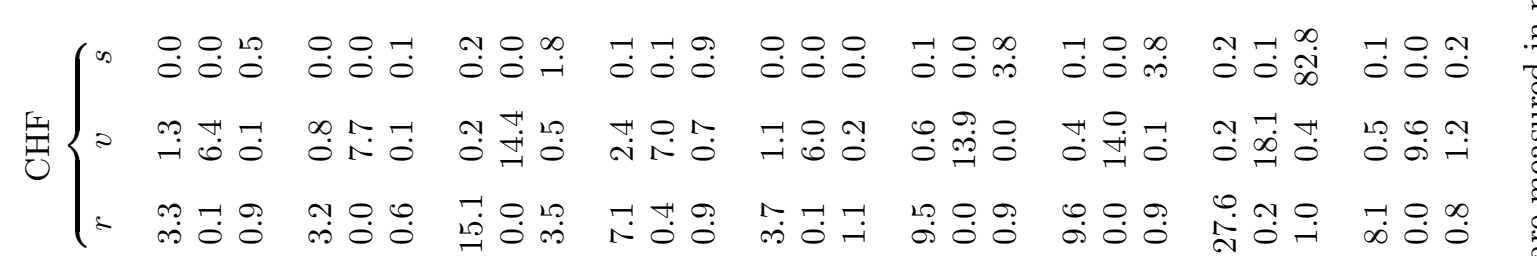

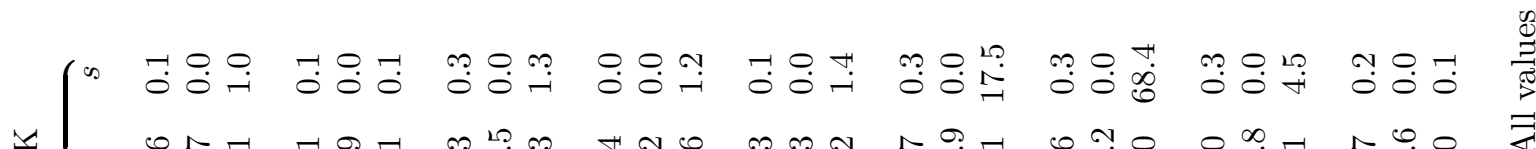

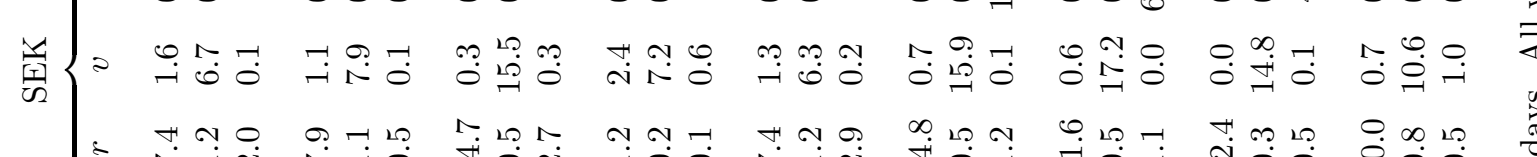

- 芒年

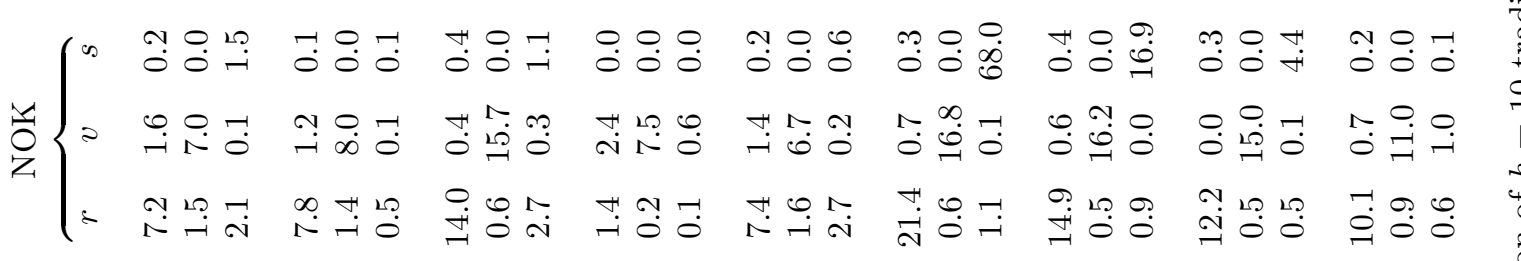

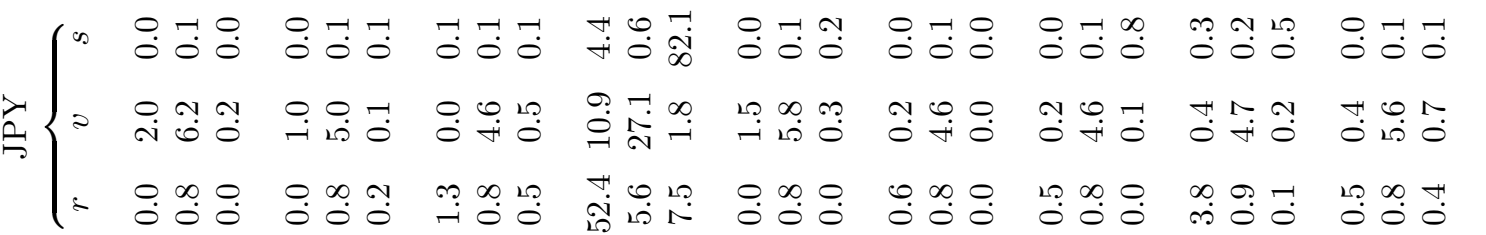

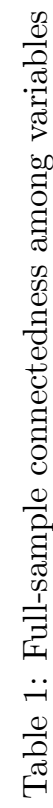

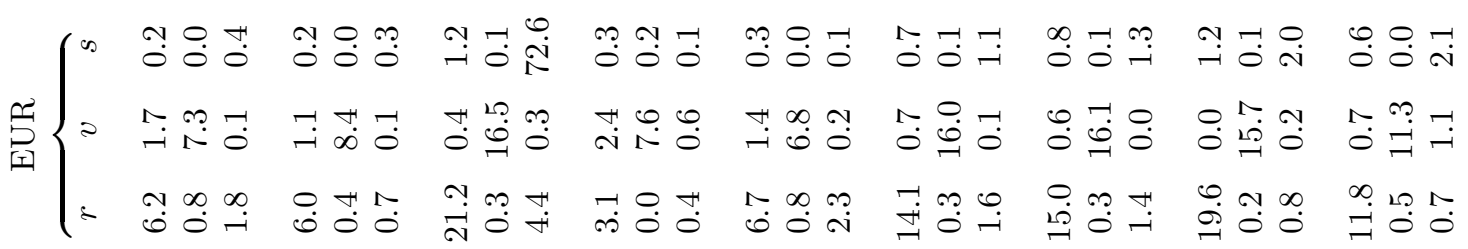

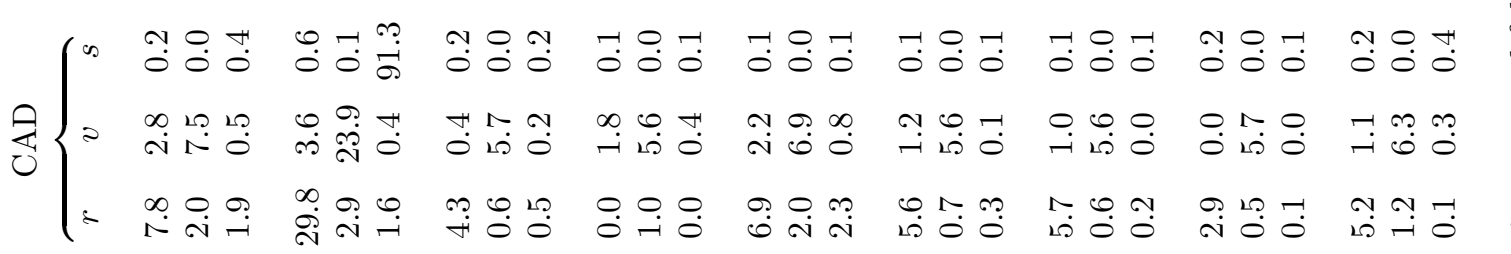

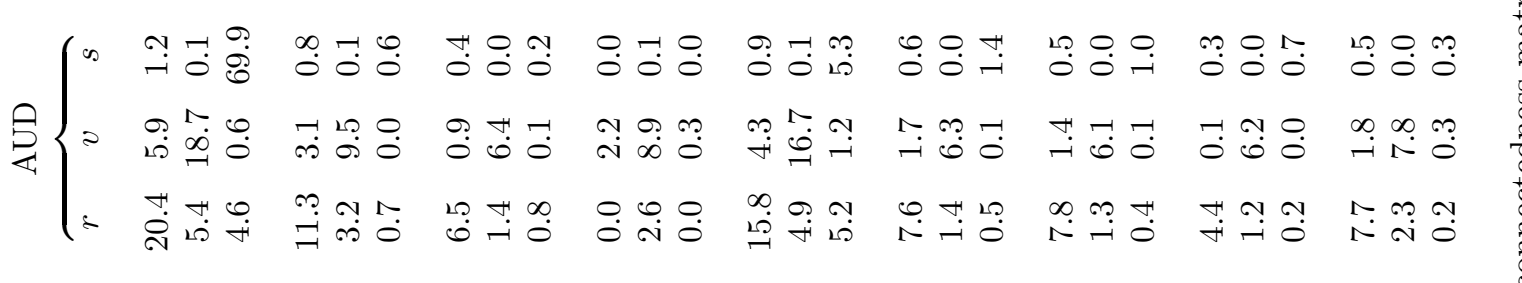

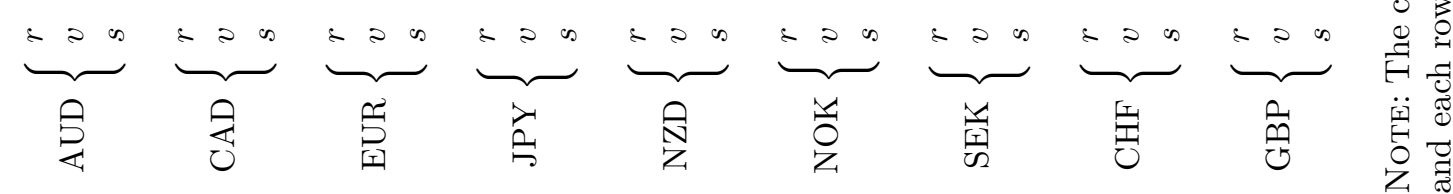




$\begin{array}{cccccccccr} & \text { AUD } & \text { CAD } & \text { EUR } & \text { JPY } & \text { NZD } & \text { NOK } & \text { SEK } & \text { CHF } & \text { GBP } \\ \text { AUD } & 42.27 & 7.68 & 6.18 & 3.12 & 16.52 & 7.11 & 6.69 & 4.22 & 6.22 \\ \text { CAD } & 9.79 & 51.42 & 5.73 & 2.47 & 8.03 & 6.40 & 6.27 & 4.18 & 5.70 \\ \text { EUR } & 5.59 & 4.04 & 39.02 & 2.68 & 5.16 & 11.73 & 11.92 & 11.90 & 7.97 \\ \text { JPY } & 4.73 & 3.05 & 4.92 & 64.12 & 4.15 & 4.08 & 4.30 & 6.54 & 4.10 \\ \text { NZD } & 18.17 & 7.13 & 6.21 & 2.94 & 41.30 & 6.91 & 6.91 & 4.05 & 6.39 \\ \text { NOK } & 6.51 & 4.55 & 11.55 & 2.13 & 5.70 & 36.33 & 16.98 & 9.62 & 6.64 \\ \text { SEK } & 6.20 & 4.46 & 11.83 & 2.35 & 5.65 & 16.84 & 36.51 & 9.65 & 6.51 \\ \text { CHF } & 4.37 & 3.19 & 13.30 & 3.64 & 3.83 & 11.00 & 11.00 & 43.51 & 6.16 \\ \text { GBP } & 6.98 & 4.93 & 9.63 & 2.91 & 6.53 & 8.19 & 7.96 & 6.84 & 46.01\end{array}$

NoтE: The market connectedness matrix is computed following Diebold and Yilmaz (2014) under the block aggregation routine devised by Greenwood-Nimmo et al. (2015a) using a forecast horizon of $h=10$ trading days. All values are measured in percentage units and each row sums to $100 \%$.

Table 2: Full-sample market connectedness matrix 


$\begin{array}{cccc} & r & v & s \\ r & 83.47 & 13.16 & 3.37 \\ v & 10.00 & 89.29 & 0.71 \\ s & 10.63 & 2.90 & 86.47\end{array}$

NotE: The moment connectedness matrix is computed following Diebold and Yilmaz (2014) under the block aggregation routine devised by Greenwood-Nimmo et al. (2015a) using a forecast horizon of $h=10$ trading days. All values are measured in percentage units and each row sums to $100 \%$.

Table 3: Full-sample moment connectedness matrix 


\begin{tabular}{|c|c|c|c|c|c|c|c|}
\hline & & $\overline{F_{t}}$ & $\underline{F_{t}}$ & $\overline{T_{t}}$ & $\underline{T_{t}}$ & $\overline{V_{t}}$ & $\underline{V_{t}}$ \\
\hline \multirow[t]{2}{*}{ Full Sample } & ${\overline{S_{t}}}^{(h)}$ & & $32 \%$ & $6 \%$ & & $13 \%$ & \\
\hline & $\underline{S}_{t}^{(h)}$ & $26 \%$ & & & $4 \%$ & & $21 \%$ \\
\hline \multirow[t]{2}{*}{ Pre-ZLB Period } & ${\overline{S_{t}}}^{(h)}$ & & $62 \%$ & & & & \\
\hline & ${\underline{S_{t}}}^{(h)}$ & $35 \%$ & & & & & \\
\hline \multirow[t]{2}{*}{ Crisis Period } & ${\overline{S_{t}}}^{(h)}$ & & & $21 \%$ & & $45 \%$ & \\
\hline & $\underline{S}_{t}^{(h)}$ & & & & $6 \%$ & & $33 \%$ \\
\hline
\end{tabular}

NOTE: Following the definition in Section $6, \overline{x_{t}}\left(x_{t}\right)$ is a binary variable indicating periods in which the variable $x_{t} \in\left\{S_{t}^{(h)}, F_{t}, T_{t}, V_{t}\right\}$ records a new high (low) relative to its historical values over the preceding 250 trading days. The table reports pseudo-hit-rates computed as in Equation (13). A "hit" is defined as a new high/low in the spillover index occurring within \pm 5 trading days of a new high/low in the named macro-financial variable $\left(F_{t}, T_{t}\right.$ or $\left.V_{t}\right)$. The full sample is from December 8, 2000 to October 14, 2014 (4,571 trading days), the pre-ZLB period is December 8, 2000 to December 31, 2008 (2,077 trading days), and the crisis period is September 15, 2008 to October 14, 2014 (1,571 trading days). The aggregate spillover index, $S_{t}^{(h)}$, is obtained using a rolling window length of $w=250$ trading days with the forecast horizon set to $h=10$ trading days.

Table 4: Pseudo-hit-rates over the full sample and selected subsamples 

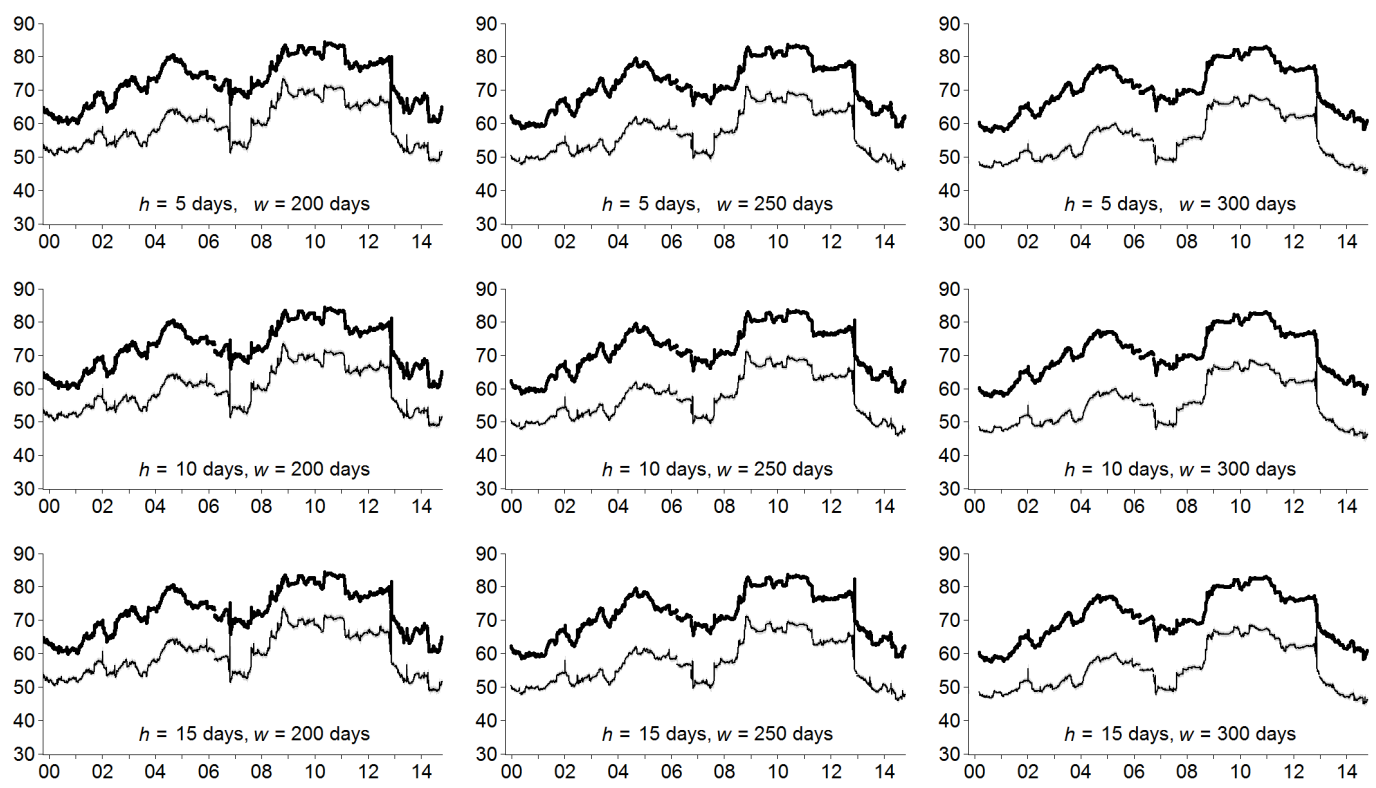

Note: We consider windows of $w=(200,250,300)$ trading days, predictive horizons of $h=(5,10,15)$ trading days, and a variety of randomly drawn Cholesky orderings. In each panel, the heavy solid line shows the rolling aggregate spillover index using orderinvariant GVDs, the gray band is the [10\%,90\%] interval based on 1,000 randomlyselected Cholesky orderings, and the fine solid line is the mean under the 1,000 Cholesky orderings. In each case, the correlation between the GVD-based spillover index and the mean of the Cholesky spillover indices is between 0.95 and 0.96 . In each panel, the $\mathrm{x}-$ axis shows time, which corresponds to the end date of the rolling samples. The unit of measurement on the $\mathrm{y}$-axis is percent.

Figure 1: Sensitivity to window length, forecast horizon, and orthogonalization 


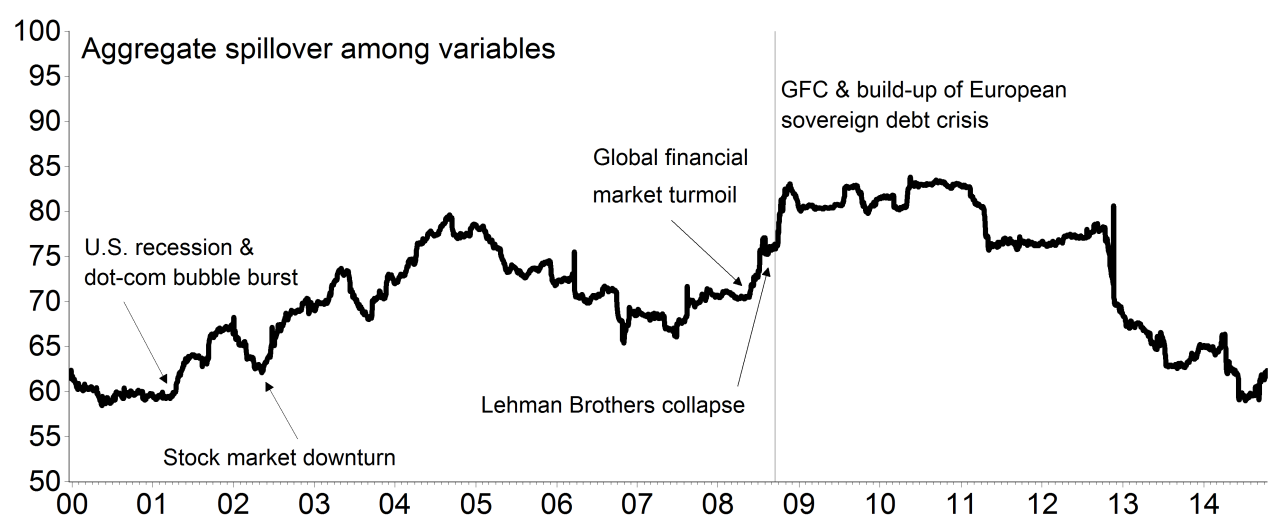

NotE: In this figure, we plot the aggregate spillover index obtained using a rolling window length of $w=250$ trading days with the forecast horizon set to $h=10$ trading days. The $\mathrm{x}$-axis shows time, which corresponds to the end date of the rolling samples. The unit of measurement on the y-axis is percent.

Figure 2: Time-varying spillover intensity 

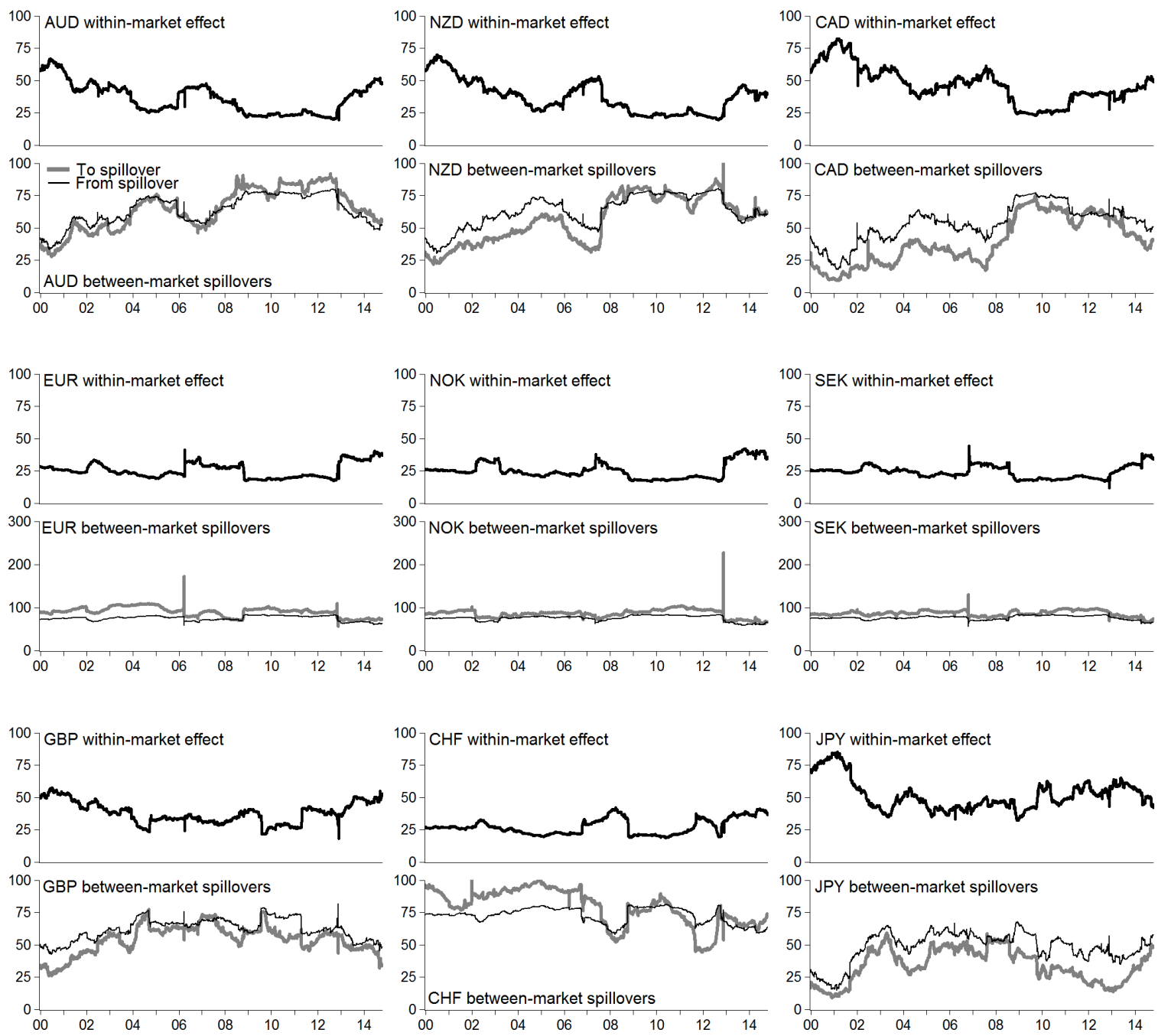

NotE: Results are obtained using a rolling window length of $w=250$ trading days with the forecast horizon set to $h=10$ trading days. In each panel, the x-axis shows time, which corresponds to the end date of the rolling samples. The unit of measurement on the y-axis is percent. Note that the "to spillover" may exceed $100 \%$ by virtue of its construction. The figure is laid out such that currencies which display similar behavior appear in the same row.

Figure 3: Rolling connectedness among markets 

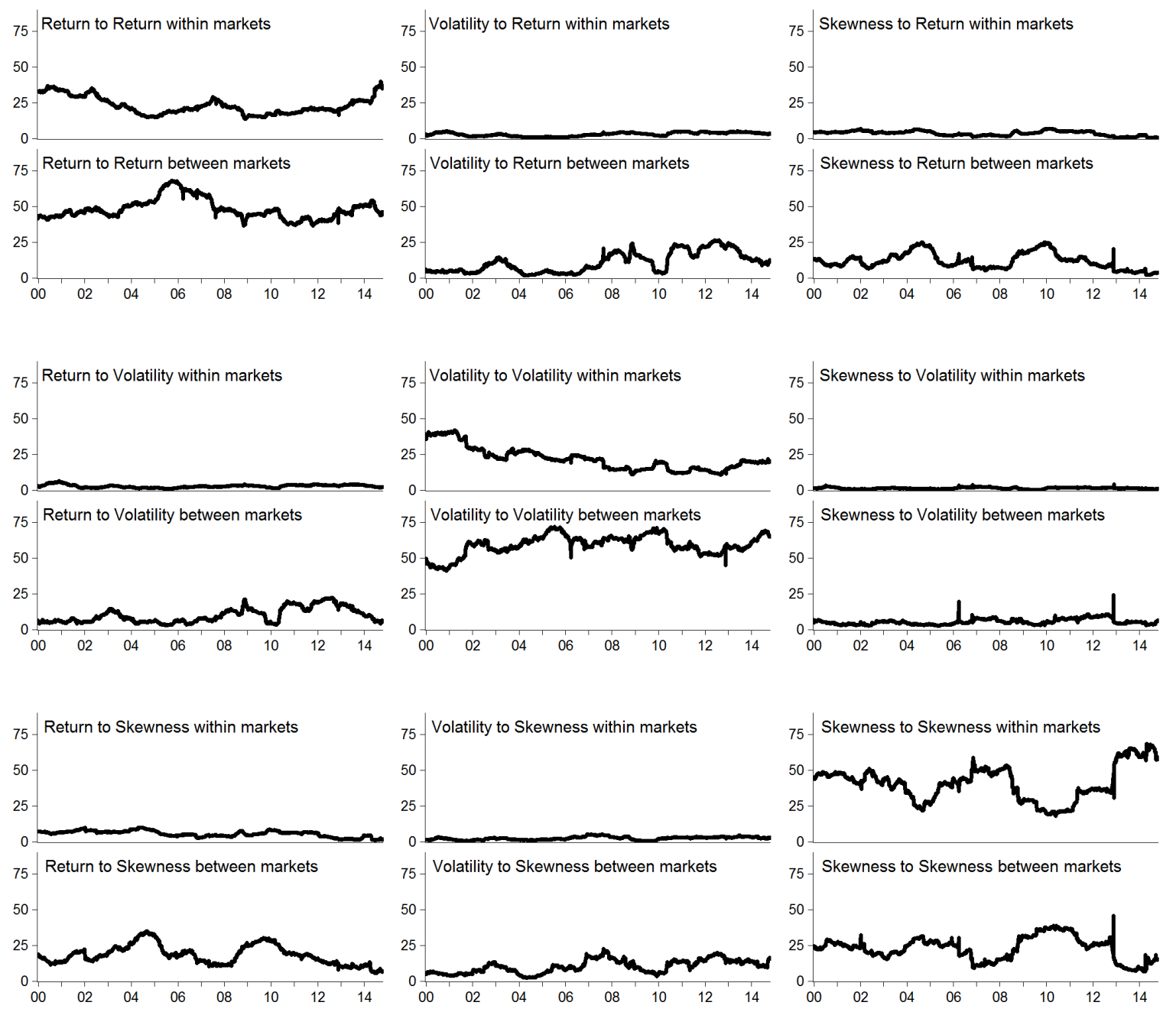

Note: Results are obtained using a rolling window length of $w=250$ trading days with the forecast horizon set to $h=10$ trading days. In each panel, the x-axis shows time, which corresponds to the end date of the rolling samples. The unit of measurement on the y-axis is percent. Further details of the block aggregation scheme used to compute these results are in the online technical supplement.

Figure 4: Rolling connectedness among moments 

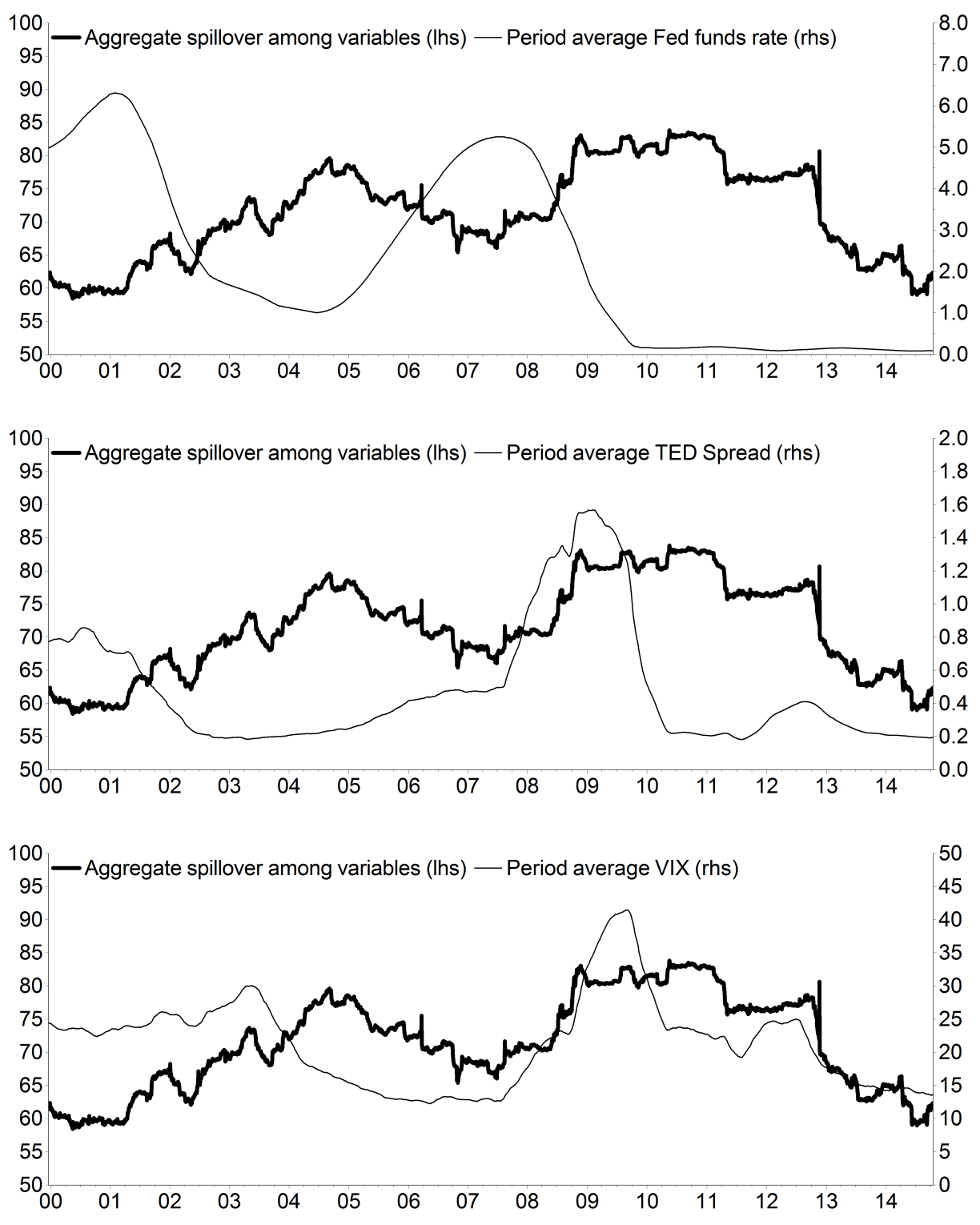

Note: In this figure, we plot the aggregate spillover index shown in Figure 2 against the period averages of the effective federal funds rate, the TED spread, and the VIX, respectively. The period average of the federal funds rate at time $t$, for example, is computed as the mean of the effective federal funds rate over the 250 trading days from $t-249, \ldots, t$. This matches the data window used to compute the value of spillover index reported at time $t$. The unit of measurement is percent for all of these variables. In each panel, the aggregate spillover index is shown on the left-hand scale and the selected financial indicator is shown on the right-hand scale. Data for the effective federal funds rate, the TED spread, and the VIX are obtained from the Federal Reserve Economic Data Service (the series IDs are "DFF," "TEDRATE," and "VIXCLS," respectively).

Figure 5: Spillover intensity versus selected financial indicators 


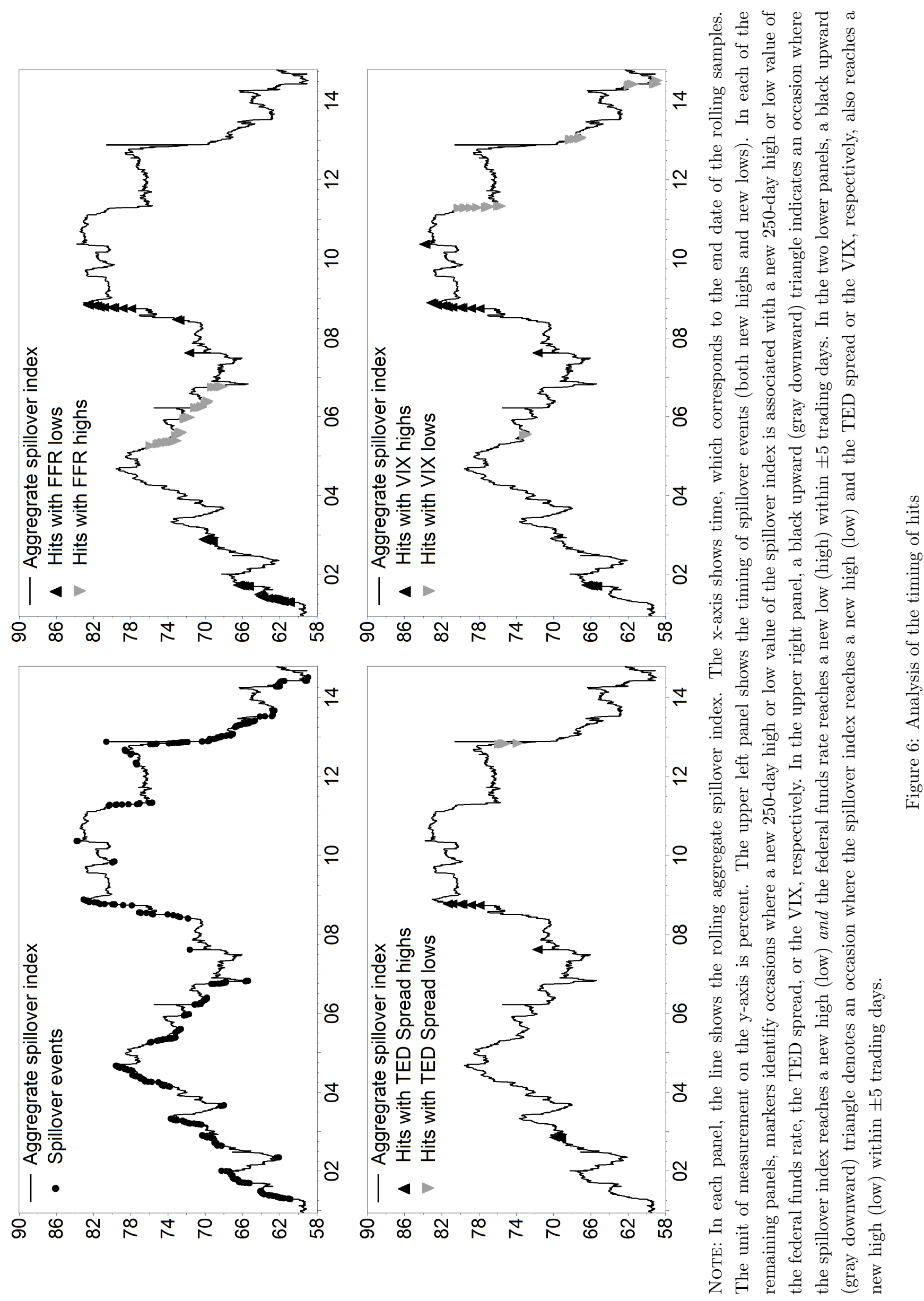

